\title{
Digital Governance and Cybernetics
}

\author{
Gilfranco Medeiro Alves \\ Universidade Federal do Mato Grosso do Sul | Brazil | gilfranco.alves@ufms.br
}

SIGRADI2018 TECHNOPOLITICAS

xxii congresso da sociedade iberoamericana de gráfica digital 22th conference of the iberoamerican society of digital graphics $07|08| 09 \mid$ novembro|2018 iau usp | são carlos | sp br
Carolina Martinez Vendimiati

Universidade Federal do Mato Grosso do Sul | Brazil | carolinavendimiati@gmail.com

\begin{abstract}
The paper studies the application of cybernetics theories in urban planning and digital governance's development. Three case studies were analyzed by cybernetics philosophers Norbet Wiener and Stafford Beer, exceptionally the relationship between 1970s Chilean experiment by Beer, CYBERSYN, and current digital governance municipalities. The methodology includes historical contextualization and followed the start, progress and the conclusion of completed cases. The results have shown the influence of private management tools applied in citizen participation.
\end{abstract}

Keywords: Cybersyn; Cybernetics; Digital Governance.

\section{INTRODUÇÃO}

Esse artigo foi desenvolvido como parte do projeto de pesquisa "Cultura Digital e Processos Digitais de Projeto" junto ao grupo Algo+Ritmo e propõe uma abordagem da teoria Cibernética aplicada ao planejamento urbano. A pesquisa visa discutir a relação histórica do primeiro experimento de governança digital no Chile, o Cybersyn, e o desenvolvimento de projetos de governança no período subsequente, destacando o uso de diferentes ferramentas de comunicação disponíveis durante o período dos experimentos. Foram analisados sob a ótica ciberneticista três casos onde o ciberespaço foi usado como ferramenta para 0 aumento da cidadania participativa: Cybersyn, no Chile, DEMOEX, na Suécia, e o Decide Madrid, na Espanha.

Os conceitos de cibernética e governança possuem em comum as suas aplicações no ambiente corporativo. O aspecto mais curioso entre ambos são suas origens diversas. A governança, oriunda do corporativismo empresarial, surgiu na necessidade de pessoas agindo como mediadoras entre os shareholders (acionistas) e os stakeholders (conjunto de atores interessados) (Bursztyn \& Bursztyn, 2012). A cibernética é um conceito que estuda as relações de comunicação e controle desenvolvido no período pós-segunda-guerra por Norbert Wiener, matemático e filósofo americano.

Governança pública é a correta consideração dos interesses dos diversos grupos que compõem a comunidade: cidadãos, gestores, instituições privadas, governamentais, organizações que realizam ações sociais. A governança pública é a redistribuição equilibrada do poder, seja para a providência de bens e serviços para o bem-estar público ou responsabilização.

O sistema de gestão pública, criado para administrar os recursos públicos usados em benefício da sociedade, é diretamente influenciado pelo modelo político vigente em nossa sociedade: a democracia.
A democracia é um modelo político registrado pela primeira vez no século XI a. C. em Atenas, cidade estado grega da antiguidade. O modelo tem como característica a consulta direta aos atores da sociedade no processo de gestão dos recursos naturais e sociais da cidade. Os atores, nesse caso, eram os cidadãos com mesma importância. Contudo, os cidadãos atenienses eram somente aqueles considerados os homens livres pela sociedade ateniense, naturais de Atenas, maiores de idade. Mulheres, estrangeiros e as outras minorias sociais, assim como na Atenas da Antiguidade, até os dias de hoje lutam pelo direito de exercer a cidadania em diversos países. (Dahl, 2001).

Outra diferença relevante entre a democracia da antiguidade e a contemporânea é a forma de participação: direta, semidireta e indireta. No sistema ateniense, todos os cidadãos se reuniam na ágora para deliberar o planejamento da cidade com o gestor eleito por eles. A escala da cidade-estado nesse período é inferior a escala do estado atual, composto por centenas de cidades: tal tamanho permitia o exercício direto da democracia, sem a necessidade de representantes eleitos. A democracia renasceu na idade moderna já aos moldes do estado nacional moderno, composto por milhares de pessoas representadas por dezenas eleitas pela maioria, caracterizada como a democracia indireta.

Um dos países que exerce a democracia de modo mais direto, em um nível superior ao demais países do mundo atualmente é a Suíça. Também denominada de Democracia Semidireta, os cidadãos suíços utilizam os referendos obrigatórios ou facultativos desde 1874, quando expressam 0 apoio ou rejeição às reformas constitucionais, leis e decisões governamentais em mais de 200 plebiscitos obrigatórios e 620 processos de votação ou eleições nacionais desde então (Kuenzi, 2018).

No Brasil, discute-se os motivos da explicita repulsa por parte da população em relação à política, que têm afastado e inibido a cooperação dos cidadãos nas 
questões de planejamento dos espaços públicos e das cidades. Segundo Soares Balestero (2012) o refluxo ou repulsa à democracia ocorre em uma série de três ocorrências que incluem o afastamento, a renúncia e, então, à repulsa política. Tais fenômenos são atribuídos à centralização do poder, a proeminência dos interesses corporativos sobre os sociais e a condescendência dos poderes com a desigualdade social.

Evidentemente, a Democracia Representativa tal como vem sendo aplicada no Brasil não favorece a participação popular na administração pública, dado que as classes menos favorecidas se sentem desassistidas. $O$ envolvimento coletivo no progresso dos projetos urbanísticos e a introdução de aspectos da democracia participativa na concepção do planejamento do meio urbano contribuiria para projetos mais adequados.

\section{CIBERNÉTICA, CIBERESPAÇO, CIBERCULTURA E CULTURA DE CONVERGÊNCIA.}

O desenvolvimento da tecnologia da comunicação permitiu a democratização do conhecimento: há tantas informações disponíveis na rede que nenhum ser humano é capaz de conter todo conhecimento sozinho. Pierre Lévy, filósofo francês, argumenta que essa transformação ocorreu devido ao avanço tecnológico dos meios de comunicação que possibilitou a formação da inteligência coletiva: processo social que usa o ciberespaço como suporte, possibilita maior participação e emancipação da comunidade através do compartilhamento de saber e experiências. (Lévy, 1999).

A cibernética, uma palavra específica derivada do radical grego kubernētēs por Wiener (1968) para o conceito de comunicação e controle, derivou o termo ciber, que se transformou de maneira imprevisível e, atualmente, é mais reconhecida pela sua relação com a microeletrônica do que pelo conceito que a originou. Hoje simboliza uma atitude, uma apropriação vitalista, hedonista, tribal, presenteísta da tecnologia. Pierre Musso (2006) com o estudo de diversos filósofos do tema e em especial Norbert Wiener, concluiu que o ciberespaço é uma "rede pensante" que conecta cérebros e computadores em escala global, sendo os computadores máquinas criadas por analogia ao cérebro humano. A cibernética é influenciada principalmente pela formação multidisciplinar de seu criador, o matemático, filósofo e biólogo Norbert Wiener, resumidamente definida como "um modelo informacional onde a relação entre o homem e o seu ambiente se estabelece a partir de trocas de informação. Essas determinam sua evolução e sobrevivência." (Lemos, 2010, p. 102).

O momento fundamental para a mudança de sentido do radical grego foi a primeira menção ao ciberespaço, na literatura ficcional. O romancista Willian Gibson (2008), autor do livro Neuromancer, obra precursora da contracultura ciberpunk, cita pela primeira vez o neologismo ciberespaço na primeira edição da obra. Em 1984, Gibson descreve "uma alucinação consensual", "apresentação gráfica de dados" de "complexidade impensável” (p. 67). No contexto da década de 1980, a informática abandona o status de tecnologia a serviço do setor industrial e começa a constituir a "infraestrutura de produção de todo o domínio das comunicações" (Lévy, 1999, p. 32).
Os estudos de Wiener forneceram material teórico para o desenvolvimento de fundamentos da gestão, administração, matemática no século $X X$ e robótica. Vivemos um contexto onde a microinformática e 0 ciberespaço influenciam em quase todas as nossas relações interpessoais. Lévy (1999) argumenta que o quadro atual representa a cibercultura, "o conjunto de técnicas (materiais e intelectuais) de práticas, de atitudes, de modos de pensamento e de valores que se desenvolvem juntamente com 0 crescimento do ciberespaço (p. 17).

$\mathrm{Na}$ esfera da gestão e planejamento urbano, o uso da comunicação via rede de internet entre os diferentes atores da sociedade contribui para a maior transparência processual na elaboração de orçamentos, disponibiliza as informações e leis e interesse da comunidade civil de modo mais acessível, seja para o público leigo ou para classes específicas (arquitetos, urbanistas, juristas). As relações existentes na cidade real abrangem então uma dimensão digital, espaço onde as relações tendem à menor verticalidade, onde as pessoas trocam informações e cooperam pela realização de um objetivo comum. Contudo, a governança digital é comumente aplicada à para a otimização da gestão dos recursos, processos, da digitalização de documentos, divulgação de dados estatísticos, arquivos, subaproveitando o potencial agregador e democrático do ciberespaço (Fusero, 2008, p. 98).

\section{METODOLOGIA}

O artigo pretende investigar e mapear algumas das iniciativas de governança digital e democracia participativa sob a ótica da cibernética, assim como a influência histórica dos ciberteóricos no desenvolvimento desses projetos. A cibernética destaca que as relações humanas só podem ser compreendidas por meio do estudo da transmissão de mensagens e que as máquinas humanas de comunicação são um aspecto adicional que pode alterar a velocidade do sistema. Logo, o verdadeiro propósito é "desenvolver uma linguagem e técnicas que nos capacitem, de fato, a haver-nos com o problema do controle e da comunicação em geral, e a descobrir o repertório de técnicas e ideias adequadas para classificar-lhe as manifestações" (Wiener, 1968, p. 17).

Os sistemas de mensagens, assim como os outros sistemas que envolvem com a ação de elementos externos, está vulnerável à entropia que desorganiza e contribui à degradação do mesmo. A linguagem e técnica de controle e regulação das mensagens é análoga ao sistema nervoso dos mamíferos: o ponto central do sistema envia mensagens (que podem ou não passar por transformação para adequação de linguagens entre os membros envolvidos) cujo receptor é um membro periférico do sistema. Esse mesmo membro possui receptores das condições externas à que está submetido e retroalimenta (feedback loop) o sistema ao enviar tais dados ao início do sistema, que submeterá as informações à análise e coordenar novas orientações. Conforme a comunicação começa a ficar comprometida, - sistema começa a se deteriorar. Por esse motivo, Wiener considerava a informação conduzida por uma mensagem o negativo de sua entropia. De modo simplificado, a mensagem enviada pelo centro é um input 
em um processo que executa as ações gerando novas mensagens (output).

O objetivo ao analisar os casos que são sugeridos no artigo é encontrar os aspectos que contribuem para a extensão do tempo de funcionamento e os motivos que os encerram. Alguns casos são experimento encerrados (CYBERSYN, Demoex) e outros em execução (Consul Project).

\section{DISCUSSÃO DOS CASOS ESTUDADOS CYBERSYN - SANTIAGO DO CHILE}

O idealizador do experimento foi o ciberneticista inglês Stafford Beer, com a contribuição nas fases de implantação dos engenheiros Raúl Espero e Fernando Flores, também diretor político do Cybersyn. O CYBERSYN, palavra derivada da expressão "cybernetic synergy", foi apoiada pelo presidente do Chile, Salvador Allende, eleito em 1970 ao oferecer um novo plano de gestão mais democrático e um instrumento de distribuição de poder. Allende governou até 1973, quando o seu mandato e o projeto CYBERSYN foram interrompidos pela deposição do presidente e a instauração da ditadura militar de Augusto Pinochet.

Allende tinha como plano de governo a transição econômica e política do país, tendo como objetivo a formação de um estado chileno socialista de forma democrática. Entretanto, a conjuntura política e social da Guerra Fria contribuiu para a pressão interna dos investidores e oposição partidária.

Fernando Flores foi nomeado subgerente técnico do CORFO (Corporação de Fomento da Produção) em 1971, a terceira posição mais alta dentro da agência cuja função era a gestão das fábricas recém nacionalizadas. Flores conheceu os princípios defendidos por Stafford Beer quando leu Decision and Control (1966) e Cybernetics and Management (1967), livros escritos por Beer que destacavam sua proposta do uso das teorias cibernéticas na gestão empresarial. (Medina, 2006). Em seguida a sua nomeação, enviou uma carta a Beer na Inglaterra, descrevendo a situação interna do Chile, desde as intenções de redistribuição de renda e recursos no país até a catastrófica situação do Estado enquanto tentava gerir as indústrias diante da pressão política, o crescimento da inflação e do déficit do Estado. A situação era vista como algo solucionável e Flores enxergava que, ao ocupar um cargo de autoridade, não somente era possível a implantação das ideias de Beer em escala nacional, como também acreditava que o pensamento cibernético na gestão do Estado chileno se tornou uma necessidade.

Flores enviou a carta com a intenção de receber conselhos de um dos maiores pensadores do planejamento e cibernética do momento, mas suas expectativas foram superadas quando recebeu a notícia que Beer gostaria de encontrá-lo para organizarem um plano de ação para a realidade chilena. O ciberneticista inglês chegou em Santiago menos de 6 meses após o primeiro contanto com o subgerente do CORFO, com o intuito de instaurar o Viable System Model (Figura 1), cujo significado em português é o Modelo do Sistema Viável. (Beer, 1972).
O CYBERSYN, ou SYNCO em espanhol, teve como inspiração o sistema nervoso, formado por componentes que usam o feedback e a auto regulação como parte de seu funcionamento. A tecnologia disponível no Chile compunha parte considerável do desafio dos organizadores: o telex, sistema de comunicação binária semelhante ao telégrafo e simplório quando comparado com os computadores com microprocessadores em desenvolvimento na época.

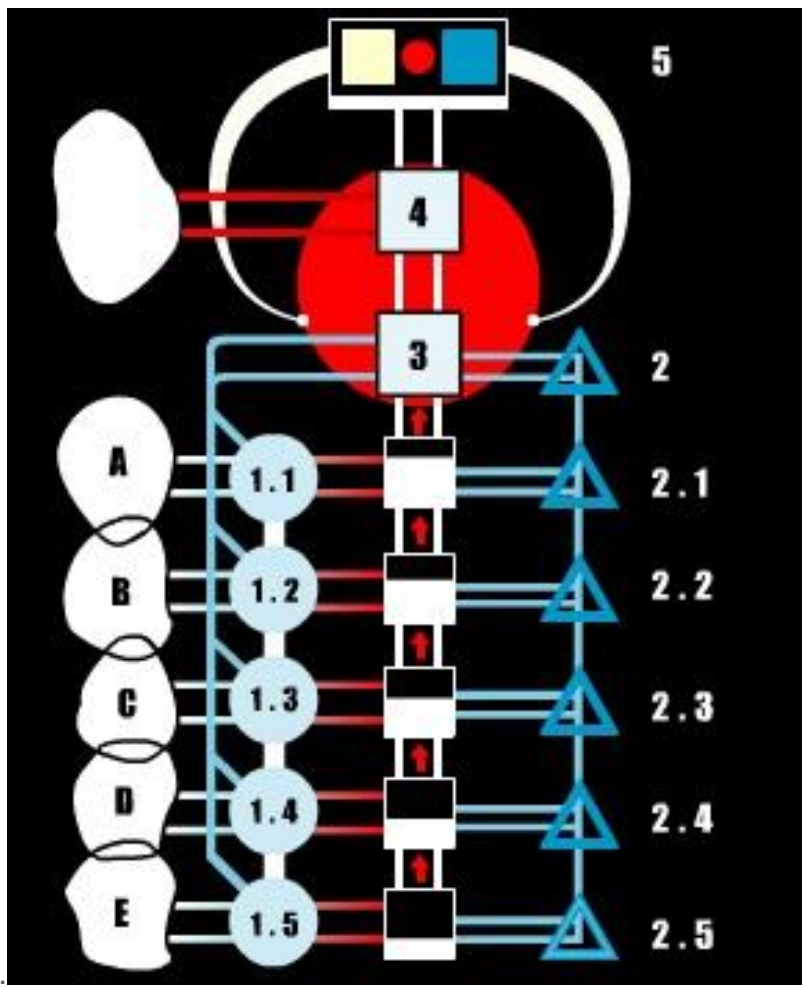

Figura 1: Diagrama representando o VSM. Fonte: $<\mathrm{https://goo.gl/RRWhFp>}$

O primeiro teste demorou mais de dois anos, em setembro de 1972. Os elementos fundamentais do CYBERSYN foram a Cybernet, Cyberstride, Projeto CHECO e Opsroom (sala de operações). A Cybernet é também chamada de a Internet Chilena e foi uma das primeiras redes de comunicação que transmitia informações cibernéticas entre o governo e a iniciativa privada. As empresas e instituições estatais estavam conectadas pela rede de 500 máquinas de telex que forneciam informações para alimentar o elemento seguinte do sistema: o cyberstride. Essa etapa consistia no processamento das informações recebidas pelas indústrias em um software de análise de probabilidades instalado em mainframe IBM 360, o computador mais avançado existente no Chile. As análises eram enviadas em linguagem compreensível aos operadores do Opsroom (Figura 2), uma sala projetada referenciando ao design de filmes e seriados de ficção científica dos anos de 1960, em planta hexagonal com sete cadeiras giratórias com um painel de botões no braço direito (Figura 3) dispostas circularmente. Esse espaço recebia e continha os dados oriundos do cyberstrade e cada uma das seis paredes comportam funções específicas, com exceção da sexta onde estava o acesso à sala. $\mathrm{Na}$ primeira, históricos de cada empresa em três slides controlados pelos botões das cadeiras, na segunda duas telas com relatórios e indicadores. A terceira e quarta eram destinadas à aplicação do VSM (Viable System 
Mode/): reprojeção de dados mais relevantes, o Painel Futuro com simulações produzidas pelo software DINAMO, criado pelo professor do MIT Jay Forrester originalmente para demonstrar a dinâmica de sistemas aplicado no funcionamento de cidades. O painel Futuro era o principal elemento estratégico do $\mathrm{CHECO}$, sigla para Chilean Economy, cujo ferramenta principal era o DINAMO. As decisões das demandas enviadas pelas fábricas eram tomadas tendo como base os resultados obtidos pelas análises de dados e estatísticas do DINAMO, conferidas pelos operadores quando continham informações suspeitas. A última parede era livre para os operadores rascunhar em um quadro de papel. O veredito era enviado novamente ao Cyberstride e, então, para as indústrias que retroalimentavam o ciclo. (Beer, 1972).

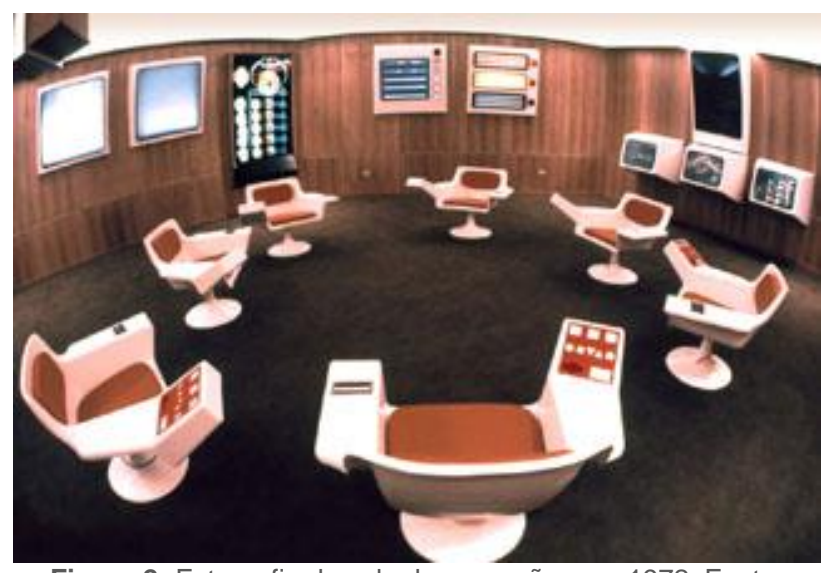

Figura 2: Fotografia da sala de operações em 1972. Fonte: https://goo.gl/Wdbjk3

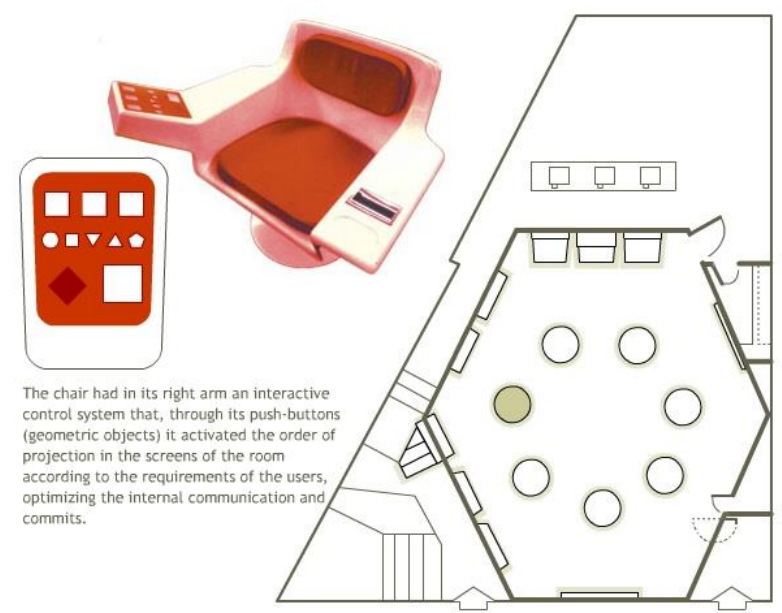

Figura 3: Planta da Sala de Operações e poltrona em destaque ao lado. Fonte: https://goo.gl/GFpNnP

A situação de fragilidade do país ocasionou a situação de teste cuja tarefa foi driblar o desabastecimento de alimentos ocorrido após a greve de caminhoneiros em 1972. O CYBERSYN foi bem-sucedido na sua tarefa, entretanto a instabilidade da política interna e a consequente tomada do poder de modo ilegítimo de Augusto Pinochet encerrou abruptamente o experimento por óbvias diferenças de valores.

A presença das máquinas de telex nas fábricas era o principal meio de participação popular no modelo organizacional de Beer. O legado do projeto foi registrado através do livro Brain of The Firm, no qual dedica seis capítulos à descrição do CYBERSYN em primeira pessoa, assim como o desenvolvimento de literatura e teorias de planejamento que se solidificaram na administração de instituições privadas. O CYBERSYN funcionou durante poucos meses, porém demonstrou as vantagens da aplicação dos conceitos cibernéticos na gestão como também a importância da rede de comunicações para uma boa governabilidade.

\section{DEMOEX}

No ano de 2002, uma iniciativa popular composta por jovens e adolescente para diminuir o pessimismo frente à estrutura hierárquica top-down deu origem ao DEMOEX (abreviação de "Demokratiexperiment") em Vallentuna, cidade à $25 \mathrm{~km}$ de Estocolmo. Partido sem posicionamento ideológico, com o principal objetivo de discutir na câmara municipal pautas políticoadministrativas decididas pela maioria da população de maneira mais direta. $O$ experimento de democracia participativa usou como suporte para a seleção de pautas o website http://demoex.se/en/, visualmente parecido com os fóruns de discussão populares na internet dos anos 2000.

O experimento e o espaço digital foram criados por voluntários e não foi reconhecido pelo Estado como ferramenta participativa (Figura 4). Para que seu objetivo fosse cumprido, um representante do projeto precisou ser eleito democraticamente nas eleições municipais, com o único e primordial objetivo de defender o posicionamento da maioria dos usuários do DEMOEX. A jovem sueca Parisa Molagholi, então com 19 anos, foi eleita.

As propostas debatidas abrangiam a criação de instituições de ensino, praças, jardins de infância, áreas verdes, melhoria da iluminação pública, privatização de bens públicos, revisão do orçamento municipal, dos limites urbanos. Houve grande contribuição dos cidadãos para a discussão na câmara acerca das decisões urbanísticas de Vallentuna.

O website DEMOEX cumpriu sua função durante 9 anos, de 2004 a 2013. Já não existe mais com a finalidade original: em 2013 nenhum representante do partido foi eleito e atualmente o domínio está disponível como um registro histórico da iniciativa. Foi criado em 2004 e suas atividades encerraram em 2013. As interações entre usuários foi progressivamente escasseando, a fraca retroalimentação causada pelo diminuto interesse dos demais atores da sociedade na câmara, raras melhorias no design do website e poucas transformações no mundo real fragilizaram o ciclo. A cidade digital começou a representar uma cidade não correspondente à material quando a última não recebe estímulos. (Lévy, 1999).

No entanto, o projeto inspirou um novo que considera os acertos e experiências negativas, o Direkt Demokraterna.

\section{PROJETO CONSUL}

Segundo o United Nations E-Government Survey 2016, um ranking elaborado pela Nações Unidas comparando o grau de interação digital entre o governo e pessoas, a Espanha está em $7^{\circ}$ lugar no quesito "E-participation". Isso significa que as pessoas do país estão em contínuo processo deliberação, consulta e troca de informações no ambiente real e virtual, participando das tomadas de decisão sejam por meio do engajamento por meio redes 
sociais ou canais específicos. O desempenho do país no ranking, seja no quesito e-participação com a $7^{\underline{a}}$ colocação ou no e-governança com o 17ª , cresceu durante os últimos anos e o principal motivador foi 0 Movimento dos Indignados, 15M em 2011.

Em 15 de maio de 2011, milhares de cidadãos espanhóis ocuparam as ruas e praças das cidades clamando por uma democracia mais direta, deliberativa e participativa. Durante um mês, a população movida pela situação de crise financeira, alto desemprego juvenil, déficit habitacional, corrupção exigia maior transparência, melhoria dos processos e instituições governamentais. Mesmo com uma cultura de fraca participação causada pela ausência de políticas de favorecimento ao engajamento e barreiras burocráticas (Peña-López, 2017), os protótipos de plataformas de tomada de decisão assistidas por tecnologia da informação inspiradas pelas ideais de democracia direta como os casos estudados anteriormente impulsionaram a construção do software open source CONSUL. O Consul é usado em 18 países, por mais de 50 municípios, desde diversas cidades espanholas como também Buenos Aires, Lima, Montevideo, Paris, Roma e Porto Alegre (figura 4).

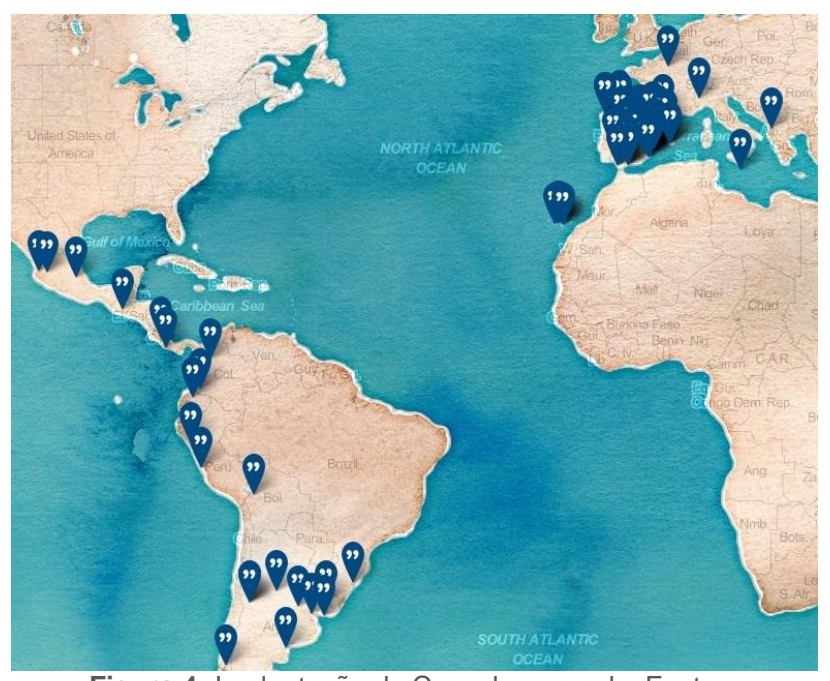

Figura 4: Implantação do Consul no mundo. Fonte:< http://consulproject.org/en/>

Após a autenticação dos residentes maiores de 16 anos, é possível debater assuntos de interesse comum, orçamentos, submeter propostas e votar. As propostas são criadas pelos cidadãos, contudo pré-requisito para ser votada como proposta é o apoio do mínimo de $1 \%$ dos eleitores (27 mil eleitores). O endereço onde ocorrem as discussões é http://datos.madrid.es/portal/site/egob, em espanhol e em duas versões: desktop e dispositivos móveis. A partir do segundo semestre de 2015, foram promovidos encontros entre cidadãos e programadores para fomentar a participação de diversos atores no processo de transparência e colaboração.

Entre 13 e 19 de fevereiro de 2017 foi realizada uma grande votação que resultou na aprovação de propostas como a criação do bilhete único para o transporte público, no vencedor do concurso de projetos de reforma da Plaza España, no comprometimento com atitudes de planejamento urbano a favor da sustentabilidade e outras questões urbanísticas como o alargamento de calçadas, implantação de mais faixas de pedestres, transporte coletivo com preferência entre os demais automóveis no trânsito. A votação foi realizada por meio do website Decide Madrid, pelo correio e urnas espalhadas pela cidade. Dos 214076 votos, 54\% foram realizados por correio enquanto 35\% utilizaram o Decide Madrid. A câmara municipal considerou um sucesso a campanha, entretanto foi bastante criticada devido ao investimento gasto no processo, cerca de 1,1 milhões de euros. O Decide Madrid atende aos 2,7 milhões de cidadãos aptos a votar dos 3,3 do total de 3,3 milhões de habitantes da cidade desde 2015.

\section{CONSIDERACÕ̃ES}

Não devemos desconsiderar os espaços de interação na rede. A cidade não é composta apenas de espaços físicos, mas ela representa uma convergência de linguagens à serviço da interação humana. A antropologia considera que o lugar é um espaço no qual lemos a identidade dos que a habitam, suas relações e sua história de maneira fortemente simbolizada (Augé, 2006).

Experiências ocorridas no intervalo entre o CYBERSYN e o DEMOEX não buscavam o incremento à democracia participativa, entretanto contribuíram para o entendimento das relações sociais em ambiente virtuais, a importância do feedback e suas consequências na vivência urbana. $O$ DDS (De Digitale Stad, Cidade Digital de Amsterdã em holandês), criada em 1990, disponibilizava informações administrativas, horários de instituições municipais, catálogo de bibliotecas e fóruns de discussão que introduziram as demandas urbanas em ambientes horizontalizados (Lévy, 1999). Na prática, funcionou como uma reprodução de informações importantes com sutis contornos de ágora digital.

O maior desafio para o uso de lugares digitais como espaço de governança é a desconfiança e a aversão à política. Desde a popularização das redes sociais, as camadas mais jovens dos eleitores e os mais familiarizados com redes socias como Facebook, Twitter e Instagram estão mais engajadas com a governança pública. Contudo, essa participação ocorre de modo apartidário e mais especificamente no acompanhamento da gestão e imagem pública dos representantes eleitos que, anteriormente, se submetiam somente à opinião de aristocratas e partidos políticos. (Jenkins, 2009).

Henry Jenkins, em Cultura de Convergência, exemplifica que mesmo um caso de democracia imaginária responde as regras do espaço material, influenciando e acrescentando substância à um ciclo maior do que o seu próprio. Em 2004 ocorreram as eleições de uma cidade totalmente virtual: Alphaville, a maior cidade no jogo The Sims Online, cujos habitantes eram os jogadores. A eleição para prefeito foi fraudada e muitos sentiam que o direito à democracia ativa estava ferido. $\mathrm{O}$ jogo, mesmo sendo um episódio ocorrido em um espaço virtual de entretenimento, gerou impactos reais, discussões nacionais e internacionais do fato. Os usuários na disputa possuíam 20 e 11 anos, o que produziu comentários como "esse é o estímulo à cidadania que queremos dar aos jovens?" após a exposição da fraude. "Para a democracia funcionar, deve haver um contrato social entre os participantes e a sensação de que suas ações têm consequências dentro da comunidade." (Jenkins,
5 
2009, p. 305). O Projeto Consul também sofreu influências de experimentos anteriores e agrega novos recursos ao exercício da governança digital. Criado há 28 anos, o OP (orçamento Participativo) de Porto Alegre é uma referência para as gestões públicas participativas e planejamento urbano. (Suptitz, 2018). A hierarquia processual do Consul foi inspirada no OP e recentemente Porto Alegre assumiu o compromisso de utilizar a plataforma (Freitas, 2017). Ambos reconhecem mutuamente que a governança digital não é uma migração e completo abandono das demais formas de consulta pública: convergindo diversos meios de comunicação e unindo-se à uma ferramenta usada mundialmente, o emprego da governança digital é fortalecida assim como sua confiabilidade.

A temática de E-governance se tornou atrativa durante a última década por consequência das vantagens orçamentárias da introdução de softwares de gestão de arrecadação de recursos públicos. Projetos como os discutidos anteriormente nesse artigo voltaram parte considerável dos seus esforços na introdução de ações que favoreceram participação dos atores mais importantes da sociedade: o cidadão da classe trabalhadora sem vínculo com os grupos mais fortemente representados e detentores da maior parte do capital privado. No Chile em 1972, os operários de fábricas participavam das decisões tomadas na Oopsroom por meio da comunicação por cabos. De maneira similar, as votações no site do DEMOEX eram representadas pelo representante eleito na câmara. O Consul propõe a participação da comunidade de modo mais direto, sem a necessidade de um representante: as informações e discussões que ocorrem no site são avaliadas, classificadas e votadas pelos usuários sem a necessidade de um intermediador político no processo.

Já é possível observar a influência de redes sociais em eleições no Brasil e nos EUA. Nesses espaços estão emergindo a todo momento discussões políticas, entretanto a plataforma não é adequada para ações de democracia participativa por serem manipuladas com a finalidade de aumentar seu valor de mercado. A implantação de softwares que possibilitem uma democracia de baixo-para-cima pode gerar efeitos positivos como a diminuição de distâncias entre os cidadãos e o poder público, maior engajamento popular, combatendo a aversão à política atual.

\section{AGRADECIMENTOS}

Agradecemos ao Conselho Nacional de Desenvolvimento Científico e Tecnológico (CNPq), A Universidade Federal do Mato Grosso do Sul (UFMS), ao grupo de pesquisa Algo+ritmo, à Berenice Maria Jacob Domingues e ao Comitê Científico Internacional do SIGraDi 2018 pela oportunidade de apresentar essa pesquisa.

\section{REFERÊNCIAS}

Art/Scicen Research Studio OR-AM. (2017). CYBERSYN. Retrieved from CYBERSYN/cybernetic synergy: http://www.cybersyn.cl/ingles/cybersyn/index.html

Augé, M. (2006). Sobremodernidade: do mundo tecnológico de hoje ao desafio essencial do amanhã. In D. Moraes (org), Sociedade Midiatizada (pp. 99-118). Rio de Janeiro: Mauad.

Beer, S. (1972). Brain of the Firm. London: The Penguin.

Bursztyn, M., \& Bursztyn, M. A. (2012). Fundamentos de política e gestão ambiental : os caminhos. Rio de Janeiro: Garamond.

Dahl, R. A. (2001). Sobre a democracia: tradução de Beatriz Sidou. Brasília: Universidade de Brasília.

DEMOEX. (2017). Information about Demoex. Retrieved from DEMOEX.net: http://demoex.se/en/

Direktdemokraterna. (2017). DIN RÖSTRÄTT MELLAN VALEN. Retrieved from Direktdemokraterna: https://direktdemokraterna.se/

Freitas, M. (2017, Novembro 08). OP: prefeitura discute acordo de cooperação internacional. Retrieved from Prefeitura Municipal de Porto Alegre: https://goo.gl/XbsQ8e

Fusero, P. (2008). E-CITY: DIGITAL NETWORKS AND CITIES OF THE FUTURE. Barcelona: List.

Gibson, W. (2008). Neuromancer. São Paulo: Aleph.

Jenkins, H. (2009). Cultura de Convergência. Sâo Paulo: Aleph.

Kuenzi, R. (2018, Maio 11). Referendos: a política sob a espada de Dâmocles. Retrieved from swissinfo: https://goo.gl/JyBEi9

Lemos, A. (2010). Cibercultura: Tecnologia e vida social na cultura contemporânea - 5aㅗ edição. Porto Alegre: Sulina.

Lévy, P. (1999). Cibercultura. São Paulo: Ed. 34.

Madrid, A. d. (2018, Junho). Consul. Retrieved from Consul Project: http://consulproject.org/es/

Medina, E. (2006). Designing Freedom, Regulating a Nation: Socialist Cybernetics in Allende's Chile. Journal of Latin American Studies, 571-606.

Musso, P. (2006). Ciberespaço, figura reticular da útopia tecnológica. In D. d. Moraes(org), Sociedade Midiatizada (pp. 191-224). Rio de Janeiro: Mauad.

Peña-López, I. (2017). Citizen participation and the rise of the open source city in Spain. ESpanha: Making all voices count.

Soares Balestero, G. (2012). O resgate da democracia participativa e deliberativa como mecanismo legitimador do exercício dos poderes estatais.Dissertação (mestrado em Constituição e Democracia). Pouso Alegre: Faculdade de Direito do Sul de Minas.

Suptitz, B. (2018, Maio 10). Madri terá votação presencial inspirada em Porto Alegre. Retrieved from Jornal do Comércio: https://goo.gl/ueG9jm

United Nations. (2017). Spain. Retrieved from UN EGovernament Knowledge Database: https://publicadministration.un.org/egovkb/enus/Data/Country-Information/id/160-Spain

Wiener, N. (1968). Cibernética e a Sociedade: O uso humano de seres humanos. 2 ed. São Paulo: Cultrix 